\title{
LA IGLESIA COMO FACTOR DE ESTABILIDAD POLÍTICA DURANTE LA RESTAURACIÓN: EL CASO DE LA RIOJA
}

\author{
Sergio Cañas Díez \\ Universidad de La Rioja, Universidad de Zaragoza, España* \\ sergio.canas@unirioja.es
}

\begin{abstract}
RESUMEN: Frente al combate contra el liberalismo que la Iglesia española libró en buena parte del siglo XIX, sobre todo en los momentos álgidos de la revolución liberal, tras el final de la I República Española y con la vuelta a la monarquía constitucional de Alfonso XII, comenzó a seguir una política más pactista con el Estado. A cambio de este apoyo, más evidente en el caso de los gobiernos conservadores que cuando gobernaron los progresistas, también la Iglesia pudo recomponerse tras el giro revolucionario del Sexenio Democrático de cara a afrontar la modernidad alcanzada por el régimen creado en 1976. Por eso queremos comprobar cómo funcionaron estos mecanismos de acuerdo en el territorio que hoy ocupa la Comunidad Autónoma de La Rioja.
\end{abstract}

Palabras clave: Iglesia-Estado, Restauración, Constitución de 1876, Alfonso XII, La Rioja.

\section{THE CHURCH AS A FACTOR OF POLITICAL STABILITY DURING THE RESTORATION: THE CASE OF LA RIOJA}

ABSTRACT: Faced with the struggle against liberalism that the Spanish Church waged in much of the nineteenth century, especially at the height of the liberal revolution, after the end of the First Spanish Republic and with the return to the constitutional monarchy of Alfonso XII, began to follow a more pactist policy with the State. In exchange for this support, more evident in the case

* Investigador postdoctoral de la Universidad de La Rioja. Miembro del GI: "Historia del siglo XX: sociedad, política y cultura", de la Universidad de Zaragoza. 
of conservative governments than when the progressives governed, the Church was also able to recompose itself after the revolutionary turn of the Democratic Sexenio in order to confront the modernity achieved by the regime created in 1976. That is why we want check how these mechanisms of agreement worked in the territory that today occupies the Autonomous Community of La Rioja.

Keywords: Church-State, Restoration, Constitution of 1876, Alfonso XII, La Rioja.

Recibido: 9 de octubre de 2018 Aceptado: 16 de diciembre de 2018

\section{Introducción}

Unas de las principales características del sistema político de la Restauración (1876-1923), es su dilatada trayectoria como sistema constitucional vigente y la estabilidad que produjo en la etapa liberal de la historia española en relación con su pasado revolucionario ${ }^{1}$. Un pasado mucho más variable y sobre el que todavía hoy se discute si hablamos de un fracaso, un retraso marcado por las coyunturas desfavorables, o una normalidad del liberalismo español frente al espacio europeo más cercano². Sin querer entrar a este debate, pese a que tiene su importancia para establecer hasta qué punto España necesitaba del régimen del 76 para alcanzar la modernidad de otros países europeos, el propio hecho de la estabilidad sí que nos parece un argumento sugerente y válido como para reflexionar en este trabajo sobre la relación que se produjo en ese periodo entre el poder político y la Iglesia española a través de la diócesis riojana³. De ese

1. Ruiz Sánchez, J. L. "Jerarquía católica y conflictividad en la Iglesia española de finales del siglo XIX. Orígenes y fundamentos", Kalakorikos, 14, 2009, p. 11. Fusi, J. P. Historia mínima de España, Madrid, Turner, 2012, p. 201. Casanova, J. y Gil Andrés, C. Historia de España en el siglo XX, Barcelona, Ariel, 2012, p. 9.

2. Véase: Fontana, J. La época del liberalismo, Barcelona, Crítica y Marcial Pons, 2007, pp. 409-410, y "Respuesta al ensayo bibliográfico de Jesús Millán", Ayer, 98, 2015, pp. 257260. Millán, J. y Romeo, M. C. “¿Por qué es importante la revolución liberal en España? Culturas políticas y ciudadanía en la historia española", en Burguera, M., y Schmidt-Nowara, C. (Eds.), Historias de España contemporánea. Cambio social y giro cultural, Valencia, Universidad de Valencia, 2008, pp. 17-43. Millán, J. "La formación de la España contemporánea: el agotamiento explicativo del fracaso liberal", Ayer, 98, 2015, pp. 243-256. Suárez Cortina, M. "Introducción. Las tradiciones culturales del liberalismo español, 1808-1950", en Suárez Cortina, M. (Eds.), Las máscaras de la libertad. El liberalismo español 1808-1950, Madrid, Marcial Pons y Fundación Práxedes Mateo Sagasta, 2003, p. 47.

3. La relación entre la Iglesia y la modernidad socioeconómica ha sido analizada en: Cañas Díez, S. "Iglesia y movimiento obrero en La Rioja (1876-1923)", Historia Actual Online, 35, 2014, pp. 93-112, y "Asociacionismo católico-riojano durante la Restauración (1876-1923)", Folguera, P. et al. (Eds.), Pensar con la historia desde el siglo XXI, Madrid, UAM, 2018, pp. 2937-2955. 
modo podemos contribuir desde este espacio provincial a construir y repensar un paradigma nacional general ${ }^{4}$. No tanto para negarlo, sustituirlo o modernizarlo, sino para asentarlo mejor, contribuir al debate y ampliar el balance historiográfico desde esta perspectiva.

A pesar de la estabilidad propia de la Restauración, no dejó ser una etapa donde se sucedieron distintas reformas encaminadas a ampliar el abanico de derechos y libertades, y no podemos olvidar que fue testigo de distintos conflictos que surgieron en su seno y que tuvieron a la Iglesia como protagonista. Así, el cambio de siglo fue un importante punto de cesura que se fue complicando con el convulso devenir histórico de las dos primeras décadas del siglo $\mathrm{XX}^{5}$. Pero valorándola en su conjunto podemos afirmar que fue una época capaz de frenar las aspiraciones de los sectores sociopolíticos más radicales del pasado revolucionario, hecho que hizo que el sistema político creado fuese atractivo para la mayor parte de la jerarquía católica que hasta esos momentos estaba instalada en un pensamiento totalmente contrario al liberalismo desde el pontificado de Pío IX ${ }^{6}$. Y más aún, durante el pontificado de León XIII se posibilitó la creación de un clima de aparente normalidad en las relaciones Iglesia-Estado que se significó por el pacto entre la élite burguesa y la jerarquía eclesiástica. A pesar de la concesión de algunas demandas básicas del estallido revolucionario de $1868^{7}$, y de la crítica del catolicismo a las reformas hechas en el periodo de la Restauración que no contaron con su aprobación, sí que tuvieron, en cambio, su debido cumplimiento y el freno a las aspiraciones católicas más intransigentes y reaccionarias.

También debemos tener en cuenta que la propia evolución del régimen articulado en torno a la Constitución de 1876 que defendía la Monarquía Constitucional y las cotas de modernidad alcanzadas paulatinamente durante varias décadas, derivan tanto del acuerdo entre las élites políticas y eclesiásticas como de la falta de una alternativa material tangible. Aunque la nue-

4. En parte nuestra idea bebe del planteamiento de la Iglesia como garantía de paz social: Gil Andrés, C. Echarse a la calle: amotinados, huelguistas y revolucionarios (La Rioja, 18901936), Zaragoza, Universidad de Zaragoza, 2000., p. 478 y Delgado Idarreta, J. M. "La Rioja", en Valera Ortega, J. (Dir.), El poder de la influencia: geografía del caciquismo en España (18751923), Madrid, Marcial Pons, 2001, p. 507.

5. Montero, F. "El catolicismo español finisecular y la crisis del 98", Studia histórica, 15, 1997, pp. 221-237. Para el espacio riojano vid. Cañas Díez, S. “Crisis de la religiosidad tradicional frente a la modernidad entre los siglos XIX-XX: el ejemplo de la Diócesis de Calahorra y La Calzada", Historia Actual Online, 43, 2017, pp. 79-89.

6. Véase: Cañas Díez, S. "Iglesia y prensa española frente a la Unificación de Italia. Sagasta y el debate sobre el poder temporal del Papa", Brocar, 34, 2010, pp. 77-114. Id. "La unificación de Italia vista por la Iglesia española: el caso de Calahorra", Kalakorikos, 16, 2011, pp. 31-77. Id. "El catolicismo español frente a la Unificación de Italia", en E. Granito, (coord.), Un popolo uno Stato, Salerno, Plectica, 2012, pp. 189-222.

7. Suárez Cortina, M. "Introducción...", op. cit., p. 27. 
va realidad que se fue configurando en España creó nuevos problemas y fue apuntalando progresivamente movimientos de signo contrario al régimen del 76 , bien fuera por oposición frontal o por tratar de conseguir nuevos avances en materia de derechos y libertades ${ }^{8}$, no llegó a haber una posibilidad real de cambio fuera del sistema constitucional. En ese sentido, los defensores y representantes de este sistema político hallaron en la Iglesia un aliado coyuntural de gran importancia debido a que todavía era una institución que podía garantizar el orden social y que gozaba de una gran implantación entre las diferentes capas de la población, a pesar de que en el clero coexistían distintas posiciones frente al sistema de la Restauración y la nueva realidad que se estaba gestando. Una de las cuales, la del integrismo católico, era totalmente contraria al pacto con el Estado liberal ${ }^{9}$. Y que también tuvieron su manifestación en la Iglesia riojana, como veremos más adelante, aunque no fuera una tendencia mayoritaria.

Dentro de las complejas y a veces tensas relaciones entre la Iglesia católica y el liberalismo en España durante la época contemporánea, dentro del clásico binomio historiográfico Iglesia-Estado, trataremos de demostrar que a pesar de las fricciones que durante el propio tiempo analizado tuvieron que afrontar, en el fondo las relaciones que dominaron fueron las del pacto, la aceptación y la colaboración ${ }^{10}$. Es decir, que así como la Iglesia aprovechó la reversión de algunas medidas de tinte laicista, revolucionarias y republicanas, por una parte, y las nuevas herramientas que la propia sociedad produjo para combatir el movimiento de secularización propio del tiempo, por otro lado, también el sistema político se benefició del freno que el clero supuso a las aspiraciones políticas y económicas que quedaban fuera del turno dinástico; el carlismo, el republicanismo y el incipiente movimiento obrero.

8. Véase: Gil Andrés, C. Protesta popular y orden social en La Rioja de fin de siglo, 18901905, Logroño, Instituto de Estudios Riojanos, 1995, y Echarse a la calle, op. cit.

9. Tal vez uno de los casos más famosos es el del obispo carlista de Plasencia, Casas Souto, y su polémica con el obispo aperturista de Salamanca, Cámara. Véase: Esteban de Vega, M. "Católicos contra liberales: notas sobre el ambiente ideológico salmantino en la Restauración", Studia Historica, 4, 1987, pp. 58-59.

10. Una tesis ya defendida en: Montero, F. "La relación Iglesia-sociedad en la España de la segunda mitad del siglo XIX", Revista de historia contemporánea, 3, 1984, p. 90. Id. "La Iglesia católica ante el sistema político de la Restauración", en Portero, F. y Tusell, J. (Eds.), Antonio Cánovas y el sistema político de la Restauración, Madrid, Biblioteca Nueva, 1998, p. 208. Robles, C. Insurrección o legalidad: los católicos y la Restauración, CSIC, Madrid, 1988. Suárez Cortina, M. "Anticlericalismo, religión y política en la Restauración", en La Parra, E. y Suárez Cortina, M. (Eds.), El anticlericalismo español contemporáneo, Madrid, Biblioteca Nueva, 1998, pp. 127-129. Callahan, W. J. La Iglesia católica en España (1875-2002), Barcelona, Crítica, 2002, p. 97. Louzao Villar, J. "Las imágenes de lo sagrado o cómo ser católico entre cambios y continuidades (C. 1875-1931)", Historia Contemporánea, 51, 2015, pp. 455-485. de la Cueva Merino, J. "Católicos en la calle: la movilización de los católicos españoles, 18991923", Historia y política, 3, 2000, pp. 55-56. 
A la luz de los datos recabados en nuestra investigación, tampoco podemos presentar la imagen reduccionista de una situación idílica precedida por una época de continuo enfrentamiento. Pues entre los efectos más visibles de esa modernidad alcanzada durante la Restauración, destacan los relacionados con los cambios político, cultural y socioeconómico que esta etapa de la historia trajo consigo. Y a consecuencia de la definitiva implantación del modelo de sociedad burguesa y sus correlativos patrones de cultura y urbanidad, el triunfo del modo de producción capitalista y sus efectos socioeconómicos y políticos, también un clima de laicismo y de anticlericalismo comenzó a apoderarse de grandes capas de población que tradicionalmente había gozado de una fuerte salud religiosa unos decenios antes, y que aún se manifestaba fuerte en la práctica de una manera mayoritaria, si bien no de manera total como a inicios de la crisis del Antiguo Régimen ${ }^{11}$. Pero sí que es cierto que en el territorio de la diócesis de Calahorra y La Calzada comenzaron a aparecer desde mediados del siglo XIX signos evidentes del inicio de un proceso sociocultural regresivo frente a los postulados eclesiales tradicionales. Hecho que originó la crítica de la Iglesia contra el poder político que lo permitía. Y fue a partir de entonces cuando se abrieron las principales fallas de la alianza que, con sus más y sus menos, se produjo entre la religión católica y la política estatal durante el reinado de Isabel II ${ }^{12}$.

Contando con una amplia biografía a nivel nacional a la que sumemos los datos obtenidos de nuestra investigación para ubicar mejor nuestra propuesta, podemos explicar desde este espacio provincial y diocesano la posición teórica religiosa y su vertiente práctica frente a los procesos generales de secularización sociocultural y laicización política vividos en España desde el final de la I República hasta la primera dictadura del siglo XX. De ese modo podemos valorar si fueron factores que contribuyeron a la estabilidad de la democracia liberal,

11. Los reportes diocesanos hechos para la Santa Sede desde finales del siglo XVIII hasta 1833 al menos así lo expresan, a pesar de las sucesivas guerras y revoluciones vividas en los reinados de Carlos IV y Fernando VII. Por ejemplo, en los tiempos inmediatamente posteriores a la Revolución Francesa se decía que las costumbres del pueblo eran buenas, la fidelidad a Dios floreciente, la vigencia de la religión católica, ardiente y celosa "contra gallorum impíos conatus ac sacrílegos insultus", y que en la diócesis se combatían los excesos revolucionarios con pronto ánimo como si fueran unos macabeos modernos. Cfr. Archivo Secreto Vaticano (ASV). Congr. Concilio. Relat. Dioec. sig. 167 b, p. 55. Carta firmada por el obispo Aguiriano en Logroño a 18 de diciembre de 1794.

12. Sáinz Ripa, E. "La religiosidad en La Rioja durante el siglo XIX", Berceo, 83, 1972, pp. 159-184. Por otro lado, tras la influencia que el factor religioso tuvo en la guerra carlista y la implantación definitiva del liberalismo en España, los obispos dieron del esfuerzo que debían hacer los sacerdotes por exhortar al pueblo a: cumplir con los sacramentos, ser devoto y observar la fe, por culpa de "los tiempos calamitosos (...) para que un católico" cumpliera "con exactitud los preceptos de las Iglesia". Cfr. ASV. Congr. Concilio. Relat. Dioec. sig. 167 b, p. 129. Relación hecha en el Vaticano del informe enviado por el obispo García Abella desde Vitoria a 26 de julio de 1846. 
como ya hemos dicho, y hasta qué punto si lo fueron. Y también nos servirá para probar una segunda hipótesis de trabajo, según la cual la misma estabilidad que sirvió para modernizar España durante la Restauración y que contó con el apoyo de la Iglesia como uno de sus pilares principales a pesar de las críticas vertidas sobre dichos cambios, originó a medio y largo plazo una realidad tan distinta a la original que contribuyó por sí misma a la propia desintegración del sistema político de la Restauración a partir de la primera década del siglo XX, a la fuga del elemento clerical como aliado accidental del Estado liberal, y al recrudecimiento de la crítica anticlerical por la identificación de la Iglesia como aliada del caciquismo, de la oligarquía burguesa y del capital.

\section{Restauración, democracia y catolicismo}

Uno de los legados historiográficos e intelectuales clásicos más importantes y fecundos que hemos recibido del sistema de la Restauración, es herencia directa del pensamiento regeneracionista y crítico de Joaquín Costa, quien a principios del siglo anterior la sustanció en dos principios básicos: la oligarquía y el caciquismo ${ }^{13}$. Una visión nada complaciente pero ajustada razonablemente a los hechos, que sin embargo no nos sirve para penetrar en la totalidad del régimen o en su naturaleza a pesar del fracaso que representó a la hora de modernizar y democratizar lo que Fusi denomina "las estructuras últimas de la vida política"14: el papel de la monarquía, las elecciones, los partidos políticos..., el propio sistema político parlamentario, en suma. Pues también el sistema de la Restauración fue "un régimen de concordia y libertad y un sistema comparativamente estable, que durante años pareció haber resuelto los grandes problemas" de España: el intervencionismo de la corona en política, el excesivo protagonismo político de las fuerzas armadas en detrimento del elemento civil, la falta de consenso constitucional, el continuo proceso constituyente, la marginación de la oposición política y el uso exclusivista del poder por parte del partido dominante ${ }^{15}$.

Si de lo que se trataba era de modernizar España y acoplarla al desarrollo europeo occidental en todos los frentes sin romper, en la medida de lo posible, con la estructura heredada del régimen isabelino, podemos entender que se consiguió parcialmente aunque generase importantes desequilibrios territoriales, de clase e individuales. Desde esta óptica, el sistema de la Restauración fue exitoso entendiendo que su interés estribó en templar la realidad política

13. Costa, J. Oligarquía y caciquismo como forma actual de gobierno en España: urgencia y modo de cambiarla, Úbeda, Asociación Cultural Ubetense Alfredo Cazabán Laguna, 2012, p. 5. Original de 1901.

14. Fusi, J. P. Historia mínima de España, Madrid, Turner, 2012, p. 201.

15. Fusi, J. P. Historia..., op. cit., p. 202. 
y social y poner fin a "los sobresaltos y vaivenes provocados por las asonadas militares, los levantamientos republicanos y carlistas y el peligro creciente de los movimientos de protesta de las clases populares", y porque lo consiguió subsistiendo durante medio siglo "con una moderada capacidad de adaptación a las circunstancias de cada coyuntura" y no mostrando síntomas de debilidad hasta la Primera Guerra Mundial ${ }^{16}$. Paradójicamente aunque en gran medida fue capaz de superar, de ir solucionando al menos, muchos de los problemas estructurales del pasado liberal que hemos comentado, lo cierto es que su propio desarrollo generó otros nuevos a los que no fue capaz de dar respuesta y que se sumaron con los problemas heredados del pasado que no fue capaz de solventar definitivamente ${ }^{17}$.

Por otro lado tenemos el problema de calificar como democrático al régimen de 1876, pues la definición de democracia en esta época acogía un buen número de acepciones. Ya los planteamientos de Súarez Cortina han dilucidado que hubo democracia liberal entendida al modo de los partidos dinásticos, el conservador liderado por Cánovas y el liberal cuyo jefe fue Sagasta, a pesar de que las críticas que suscitó el propio sistema y la contestación al régimen "en lo que a la izquierda burguesa se refiere", se asentase "sobre la afirmación de la democracia como elemento fundamental de su identidad y cultura política". Desde este otro punto de vista se criticaba "el carácter doctrinario de la Constitución, la falta de representatividad del sistema y la necesidad de dar autenticidad a la vida política, de restaurar una soberanía nacional secuestrada por la dinastía borbónica y la clase dirigente conservadora". Sobre todo este fue el caballo de batalla del republicanismo de la época. E incluso frente a la inexistencia de una democracia representativa verdadera, sin falseamientos y caciquismos, los más radicales propusieron la alternativa de la democracia directa ${ }^{18}$.

La Restauración se propuso liquidar el sufragio universal masculino de 1868 y el sistema democrático de la I República para asentar en España la monarquía constitucional: un régimen mucho más moderado pero más estable desde el que poder modernizar el país contando con el acuerdo de los dos principales partidos. Es decir, desde el prisma de una democracia liberal distinta a la democracia republicana, que en esta época se traducía en ganar estabilidad aún a costa de perder libertad. Desde luego que las distintas manifestaciones y desarrollos del término democracia nos obligaría a atender a las diferentes culturas políticas y a la generación de los integrantes de dichos colectivos, pero, la formulación general a la que hemos aludido es lo suficientemente flexible como para contener a la mayoría dinástica, conservadora y liberal y neutralizar

16. Casanova, J., y Gil Andrés, C. Historia de España..., p. 32.

17. Fontana, J. La época..., op. cit., p. 10.

18. Suárez Cortina, M. "Radicalismo y reformismo en la democracia española de la Restauración", Berceo, 139, 2000, pp. 50, 52 y 58. 
a republicanos, demócratas radicales, integristas y $\operatorname{carlistas}^{19}$. El régimen de la Restauración era conservador en su concepción, no obstante nacía de un pronunciamiento militar pese a no ser la opción querida por Cánovas, porque establecía la soberanía nacional compartida entre las Cortes y la Corona, restringió inicialmente el sufragio, y establecía el catolicismo como religión estatal. Pero lo cierto es que progresivamente incorporó algunos principios democráticos: el sufragio universal masculino, los juicios por jurados, el culto privado de otros credos, la libertad de imprenta, el matrimonio y el entierro civil, la libertad de asociación, etc., aunque con ello en ningún momento otras opciones políticas podían romper con el bipartidismo y tampoco España pudiese equipararse con otras monarquías democráticas europeas ${ }^{20}$.

Tal vez el mayor logro del sistema del 76 se deba al propio carácter ecléctico de la propia constitución al decir de Jover Zamora: muy firme en sus bases conservadoras pero suficientemente ambigua en su articulado para permitir cierta renovación en las claves que apuntamos antes ${ }^{21}$. Mostrándose como un sistema que podía posibilitar la convivencia pacífica, el desarrollo fructífero y la prosperidad económica capitalista, el clima social de la nación "era favorable a una alternativa política que defendía el orden, la estabilidad, la seguridad"22. Así, podemos entender que "el régimen de la Restauración representó un paso adelante en el camino hacia la democracia"23, a pesar de que en el fondo no dejaba de ser una cortina de humo en la democratización real de las instituciones ${ }^{24}$. Incluso podemos asegurar que no existía tal finalidad porque el voto no decidía el Parlamento y por ende el control del poder ejecutivo, sino que era la prerrogativa regia la que decidía el gobierno. Luego los dos partidos del pacto se repartían los escaños, se nombraban los gobernadores civiles y éstos pactaban con las élites provinciales y locales para ama-

19. Suárez Cortina, M. "El liberalismo democrático en España: de la Restauración a la república", Historia y política, 17, 2007, pp. 123-125.

20. Esdaile, C. La etapa liberal: 1808-1898, en J. Lynch, (Dir.), Historia de España, vol. 17, Madrid, El País, 2007, p. 379.

21. Jover Zamora, J. M. "La época de la Restauración. Panorama político-social, 18751902", en Tuñón de Lara, M. (Dir.), Historia de España, vol. VIII, Barcelona, 1981, p. 286.

22. Avilés, J. Elizalde, M. M. y Sueiro, S. Historia política de España 1875-1939, Madrid, Istmo, 2002, pp. 17-18. Tampoco conviene olvidar que si bien no triunfó ningún movimiento político contrario a la Restauración, el periodo no estuvo carente de conflictos políticos violentos. Véase: González Calleja, E. "La razón de la fuerza. Una perspectiva de la violencia política en la España de la Restauración", Ayer, 13, 1994, pp. 85-114.

23. Avilés, J. Elizalde, M. M. y Sueiro, S. Historia..., p. 10.

24. Aunque España fuera pionera en establecer el sufragio universal masculino frente a Italia o Reino Unido, por ejemplo, realmente el falseamiento de los resultados electorales distanciaba mucho el régimen del 76 y otros sistemas liberales europeos. Véase: Valera Ortega, J. Los amigos políticos: partidos, elecciones y caciquismo en la Restauración (1875-1900), Madrid, Marcial Pons, 2001. Súarez Cortina, M. La España liberal (1868-1917). Política y sociedad, Madrid, Síntesis, 2006. 
ñar las elecciones y garantizar el resultado ya planteado, donde la figura del cacique cobraba especial importancia ${ }^{25}$. Era la contraposición entre la España oficial y la España real ${ }^{26}$.

En una clave más crítica otras interpretaciones apuntan que la Restauración "constituyó en todo momento un intento sistemático de cercenar las demandas de democratización de la población" ya que "acentuó su inflexibilidad cuando la sociedad española mostró síntomas francos de modernización"27. Pero también debemos considerar que a pesar de la falta de calidad democrática y de "valores y prácticas democráticas" en el régimen de La Restauración ${ }^{28}$, fruto "de la desconfianza genérica" del liberalismo "hacia las iniciativas de la sociedad civil y del pesimismo concreto sobre la capacidad de los electores" ${ }^{\prime 29}$, lo cierto es que contribuyó a estabilizar el liberalismo "en el contexto de la Europa de su tiempo, en que el fraude electoral gubernamental se combinaba y administraba sabiamente para integrar intereses e influencias locales (...), en contraste con el exclusivismo y monopolio de partido, en el poder, intransigencia y exterminio político del rival, retraimiento parlamentario y conspiración, rebelión y golpismo de partido, en la oposición" ${ }^{\prime 30}$.

Pasando a mirar el concepto de democracia desde las filas católicas-eclesiales Ilamamos la atención sobre su inexistencia: no hemos encontrado ninguna definición de democracia, ni tan solo una mención por parte del clero en las actas capitulares del cabildo catedral de Calahorra, en ningún número del Boletín Eclesiástico de la diócesis, ni en ningún documento enviado a la Santa Sede desde la región apostólica riojana, durante el periodo analizado. Sí, en cambio, una recomendación de la nunciatura "prohibiendo a los eclesiásticos toda manifestación política" por ser el germen "de las deplorables divisiones que siguen aquejando a los católicos españoles" ${ }^{\prime \prime}$, transmitida literalmente por el obispo Cascajares al resto del clero y que comprobamos fue obedecida de forma mayoritaria $^{32}$. Por ello entendemos que en el contexto de la Restauración la Iglesia

25. Cajas Valero, A. El Gobernador civil y el Estado centralizado del siglo XIX, Madrid, Ministerio de Administraciones Públicas, 1999, p. 108. Casanova, J. y Gil Andrés, C. Historia..., op. cit., pp. 11-13.

26. Seco Serrano, C. De los tiempos de Cánovas, Madrid, Real Academia de la Historia, 2004, p. 23.

27. Artola, M. Partidos y Programas políticos, 1808-1936. I. Los partidos políticos, Madrid, Alianza, 1991, pp. 322-323.

28. Fontana, J. La época..., op. cit., p. 438.

29. Sierra, M. Peña, M. A. y Zurita, R. Elegidos y elegibles. La representación parlamentaria en la cultura del liberalismo, Madrid, Marcial Pons, 2010, pp. 411-412.

30. Varela Ortega, J. "Introducción", en J. Varela Ortega, (Dir.), El poder..., p. 12.

31. Archivo Catedralicio y Diocesano de Calahorra (ACDC), Serie, Libros de actas, Sig. 181, 31 de octubre de 1888.

32. ACDC, Serie, Guía inventario de los antiguos legajos ss. XIX, Sig. 800/12-40, 31 de octubre de 1888. 
riojana, al igual que la española, permaneció más anclada en el pasado que en general la clase política española, "en el sentido de que en ésta encontramos un pluralismo inexistente en aquélla", por "la ausencia de un catolicismo liberal, germen de polémicas (...) pero también de creatividad y renovación" como ocurría en otras iglesias europeas ${ }^{33}$. No obstante, nuevas investigaciones apuntan a que la militancia católica sí había interiorizado "una vivencia religiosa y espiritual inseparable de su participación pública" ${ }^{\prime 34}$, mientras que el resto permanecieron pasivos dentro de un cómodo marco simbólico al que tampoco fueron ajenos los laicos ${ }^{35}$.

Y es que tan importante como la democratización política formal y la consolidación del modelo económico capitalista, es la cuestión religiosa dentro de los grandes debates políticos y constitucionales del siglo XIX español, en donde la etapa de la Restauración representa un punto interesante para conocer el paso a la modernidad de la Iglesia y su contribución al relativo éxito de la democracia liberal que acabamos de comentar ${ }^{36}$. Un problema histórico del liberalismo, la relación con la Iglesia y la nueva concepción política de la religión si la contraponemos a los tiempos absolutistas, que se llega a resolver momentáneamente en este periodo porque "las posiciones de los demócratas liberales como de los neocatólicos son rechazadas en nombre de una confesionalidad compatible con la tolerancia religiosa de la Constitución canovista" ${ }^{\prime \prime 7}$. De hecho, el diseño conservador de la Restauración borbónica establece en el Manifiesto de Sandhurst, de 1 de diciembre de 1874, que Alfonso XII será buen español, católico y liberal, lo que nos está diciendo desde el primer momento las claves del régimen posterior y resalta la importancia del hecho religioso ${ }^{38}$. Las premisas de monarquía constitucional, soberanía compartida entre el parlamento y el rey y el catolicismo como credo oficial, son tres de los elementos básicos que recuperan una tradición española católica conservadora y liberal pero a la que se añade la idea más progresista de tolerancia religiosa, porque España debía

33. Laboa, J. M. La Iglesia del siglo XIX. Entre la Restauración y la Revolución, Madrid, Universidad Pontificia de Comillas, 1994, p. 286.

34. Louzao Villar, J. "Las imágenes de lo sagrado o cómo ser católico entre cambios y continuidades (C. 1875-1931)", Historia Contemporánea, 51, 2015, pp. 455-485.

35. Louzao Villar, J. Soldados de la fe o amantes del progreso. Catolicismo y modernidad (1890-1923), Logroño, Genueve Ediciones, 2011.

36. Barrón García, J. I. La cuestión religiosa en España, 1875-1912. Iglesia y Estado. Clericalismo y anticlericalismo, Madrid, Ediciones 19, 2015.

37. Suárez Cortina, M. "La ideología liberal en la historia del constitucionalismo español del siglo XIX: la cuestión religiosa", en Caballero, J.A. Delgado, J. M. y Viguera, R. (Eds.), EI debate constitucional en el siglo XIX. Ideología, oratoria y opinión pública, Madrid, Marcial Pons, 2015, pp. 51-52.

38. Incluso planea la idea del liberalismo como religión civil en algunos de sus aspectos: Capellán, G. "El problema religioso en la España contemporánea: Krausismo y catolicismo liberal", Ayer, 39, 2000, pp. 207-244, y Box, Z. "La tesis de la religión política y sus críticos: aproximación a un debate actual", Ayer, 62, 2006, pp. 195-230. 
ajustarse a su tiempo, a las naciones modernas, y Cánovas debía buscar un punto de acuerdo con Sagasta ${ }^{39}$. Si no se llegó a modernizar totalmente el tema religioso fue porque la tolerancia religiosa era el límite aceptado por el catolicismo español en su acuerdo con el Estado liberal, y eso "no podía ser una vía suficiente para garantizar la libertad de las conciencias" ${ }^{\prime 4}$.

Lo cierto es que vemos como uno de los pilares canovistas "por mantener despolitizada a la masa fue la alianza de facto concluida por el régimen de la Restauración con la Iglesia", porque "aunque la mayoría de los clérigos detestaba el liberalismo", la jerarquía eclesiástica prefirió llegar a un acuerdo en tanto en cuanto se daba cuenta de que "Cánovas estaba dispuesto a realizar concesiones sustanciales" ${ }^{\prime 1}$. La reducción al mínimo de la libertad de cultos, el aumento del presupuesto de culto y clero, el derecho a regir escuelas propias, la multiplicación del número de monjes, quince veces superior en 1910 que en 1867, el combate estatal contra el movimiento republicano y socialista, su defensa de los preceptos básicos del catolicismo y la represión del anticlericalismo popular, así lo confirman ${ }^{42}$. La Iglesia y el régimen canovista eran aliados coyunturales y socios a la fuerza porque se necesitaban mutuamente para lograr sus objetivos particulares ${ }^{43}$.

Desde el prisma eclesial con la Restauración tiene lugar la recuperación de la posición institucional política y sociocultural de la Iglesia ${ }^{44}$. Por un lado por lo que se ha dado en Ilamar el sentimiento religioso de pertenencia a un colectivo, que la modernidad política y la organización capitalistas del trabajo iba transformando en individualismo, pero también, por el marco jurídico propicio para que la Iglesia pudiera expandirse en la sociedad mediante el movimiento católico y ciertos privilegios legales ${ }^{45}$. Por parte de los planteamientos constitu-

39. La situación de España en comparativa internacional en: Barrón García, J. I. La Iglesia católica y los estados de Europa Occidental y Norteamérica 1875-1912, Madrid, Ediciones 19, 2015.

40. Suárez Cortina, M. Entre cirios y garrotes. Política y religión en la España contemporánea, 1808-1936, Cuenca, Universidad de Castilla La Mancha, 2014, p. 66.

41. Esdaile, C. La etapa liberal..., op. cit., p. 364.

42. Además de la devolución de bienes incautados tras la revolución del 68, debemos considerar la importancia de la multiplicación del presupuesto de Culto y Clero: de 3,2 millones en 1870-1871 hasta 41,6 millones en 1874-1875. Véase: Martí Gilabert, F. Politica religiosa de la Restauración, 1875-1931, Madrid, Rialp, 1991, p. 32.

43. Preston, P. "Persecuted and Persecutors: Modern Spanish Catholicism", European History Quarterly, 20, 1990, p. 286. Martí Gilabert, F. Política religiosa de la Restauración (1875-1931), Madrid, 1991, pp. 30 y ss. Idea también recogida en: de la Cueva, J. Clericales y anticlericales. El conflicto entre Confesionalidad y Secularización en Cantabria (1875-1923), Santander, Universidad de Cantabria, 1994, p. 30 y ss.

44. Véase: Ramón Solans, J. F. “'El catolicismo tiene masas'. Nación, política y movilización en España, 1868-1931", Historia Contemporánea, 51, 2015, pp. 427-454.

45. Revuelta González, M. "La recuperación eclesiástica y el rechazo anticlerical en el cambio de siglo “, en García Delgado, J. L. (ed.), España entre dos siglos (1875-1931). Conti- 
cionales se quiso unir al catolicismo y cerrar sus filas en torno al régimen del 76, donde la idea del nacionalcatolicismo era la clave pese a que no se incluyese en la legislación ${ }^{46}$. Su éxito fue relativo porque además de contestarse desde la izquierda del régimen, fuera o no parlamentaria, también el núcleo duro del catolicismo agrupado en torno al integrismo se opuso ${ }^{47}$. "Si la unidad católica expresaba el imaginario del moderantismo, la compatibilidad entre orden y libertad, entre catolicismo confeso y tolerancia religiosa, era el ámbito que durante décadas impulsó el nuevo orden político de la Restauración" ${ }^{\prime 48}$. Además, debemos tener en cuenta para entender mejor el por qué de este tímido avance, que la libertad de cultos era uno de los caballos de batalla del progresismo anterior: para Sagasta no era transigible nada que no fuera la libertad religiosa y nunca renunció a una Iglesia que ayudase al Estado "a castigar de igual manera las dos intransigencias entre las cuales está viviendo el país con grandes penalidades y grandes amarguras; (...) Así es como podremos mantener las relaciones entre el Poder civil y la Iglesia"49. Dicho de otro modo:

La España de la Restauración no fue, sin embargo, el momento histórico del integrismo, sino de aquella posición nacionalcatólica que desde el conservadurismo liberal confrontó abiertamente con la que desde el liberalismo dinástico y antidinástico sostuvieron los defensores de una lectura más abierta del tema religioso ${ }^{50}$.

Tras la tensión anticlerical del Sexenio Revolucionario, la Restauración se presentaba pues como un periodo de relativa paz en la que la Iglesia pudo recuperar gran parte de su influencia sociopolítica y de su capacidad económica ${ }^{51}$. En materia política, también el triunfo del conservadurismo terminó con los ataques a la Iglesia y aunque no cedió ante todas las pretensiones del clero español porque respetó la libertad de conciencia privada, al modo euro-

nuidad y cambio, Madrid, 1991, pp. 213-234. Montero, F. El movimiento católico en España, Madrid, Eudema, 1993. de la Cueva, J. "Católicos en la calle: la movilización de los católicos españoles, 1899-1923", Historia y política, 3, 2000, pp. 55-80. Id. "Clericalismo y movilización católica en la España de la Restauración”, en de la Cueva Merino, J. y López Villaverde, A. L. (coord.), Clericalismo y asociacionismo católico en España: de la restauración a la transición, Cuenca, Universidad de Castilla-La Mancha, 2005, pp. 27-50.

46. De hecho ya es conocida y fecunda la idea de que asistimos al nacimiento del nacionalcatolicismo en estos momentos de la historia: Botti, A. Cielo y dinero. El nacionalcatolicismo en España (1871-1975), Madrid, Alianza, 1992.

47. Véase: Montero, F. "El peso del integrismo en la Iglesia y el catolicismo español del siglo XX", Melanges de la Casa de Velázquez, 44, 2014, pp. 131-156.

48. Suárez Cortina, M. Entre cirios y garrotes. Política y religión en la España contemporánea, 1808-1936, Cuenca, Universidad de Castilla La Mancha, 2014, p. 62.

49. Diario de Sesiones del Senado, legislatura de 1901, $n^{\circ}$ 55, pp. 882-885.

50. Suárez Cortina, M. Entre cirios y garrotes..., op. cit., p. 66.

51. Callahan, W. J. La Iglesia católica en España (1875-2002), Barcelona, Crítica, 2002, p. 35. 
peo y americano, sí que oficializó el culto católico y trató de buscar el apoyo institucional de la Iglesia para con el Estado, lo que fue la impronta religiosa más genuinamente española ${ }^{52}$. Era "una política de término medio más cercana, de hecho, al catolicismo militante que al anticlericalismo liberal" que a pesar de no satisfacer al catolicismo más ultramontano y reaccionario ni al liberalismo más radical y revolucionario, sentó las bases de una restauración pretendidamente equidistante entre el Estado y la Iglesia ${ }^{53}$. Y la verdad es que la jugada de Cánovas le salió bien al principio: satisfizo a antiguos moderados y unionistas ahora conservadores en gran medida y aisló tanto a los reaccionarios como a los liberales revolucionarios. Y lo que fue más importante, logró el pacto con el liberalismo progresista y permitió que España avanzase de cara a impulsar de nuevo un giro hacia la modernidad, lo que fue a medio y largo plazo un combate para ganarse el favor de varios sectores de la sociedad. Este equilibrio, pese a no ser absolutamente pacífico, posibilitó que los problemas y tensiones pudiesen ser arbitrados por el Estado hasta que la desintegración del mismo y su caída, puso de relieve que la solución solo había sido temporal y accidental.

La alianza burguesía-catolicismo se expresa abundantemente, especialmente como reacción defensiva ante la revolución social. (...) En la práctica, dicha alianza burguesía-catolicismo se concreta en la promoción y financiación de iniciativas benéfico-asistenciales y educativas, que se plantean a la vez como obras de recristianización y de control social ${ }^{54}$.

\section{La Iglesia riojana de la Restauración}

Dentro del estudio de esta diócesis, de esta región apostólica, vemos que los tiempos son importantes para explicar el desarrollo general que acabamos de plantear. Así, desde 1874 hasta 1877 lo cierto es que no podemos hablar del triunfo del ideal católico liberal anterior. Al revés, el liberalismo era negado y condenado por la Iglesia de Pío IX, y solo se entendía como el triunfo de la separación del Estado y de la Iglesia tal y como defendían los postulados progresistas $^{55}$. Entre 1874 y 1875 además de persistir en la prensa diocesana el

52. Payne habla de la búsqueda de apoyo del liberalismo en el catolicismo para ganarse esa "cultura tradicional" que "seguía viva en gran parte de la sociedad española". Véase: Payne, S. G. El catolicismo español, Barcelona, Planeta, 2006, p. 133.

53. Suárez Cortina, M. "Anticlericalismo, religión y política en la Restauración", en La Parra, E. y Suárez Cortina, M. (Eds.), El anticlericalismo..., p. 129.

54. Montero, F. "La relación...", p. 90.

55. Suárez Cortina, M. "El liberalismo democrático en España: de la Restauración a la República", Historia y política, 17, 2007, pp. 130-131. 
recordatorio del Syllabus, se defendían los principios ultramontanos ${ }^{56}$. Al fin y al cabo era una postura reaccionaria y defensiva ante los "agravios" revolucionarios sufridos a manos de gobiernos liberales desde $1868^{57}$. Por eso el obispo Catalina del Amo tuvo que ordenar a finales de 1875 celebrar un Te Deum por la elevación de Alfonso XII al trono, ya que el cabildo catedral de Calahorra se había negado a hacerlo a principios de año cuando el ayuntamiento se lo pidió, argumentando que no se hacía por los males de la Iglesia ${ }^{58}$. Solo una vez aprobada la Constitución de 1876 y garantizado el confesionalismo católico nacional y la vigencia del Concordato de 1851, que será usado para defender el terreno ganado ahora, es cuando observamos la entrada del clero diocesano en la política de la Restauración. No sin ciertas polémicas. Tal fue así que el prelado readmitió a algunos presbíteros con antecedentes carlistas tras el final de la Tercera Guerra Carlista, toda vez se hubieron significado anteriormente por el legitimismo pero ahora sin rechazar esa postura política pedían volver a la senda y al seno oficial de la Iglesia riojana ${ }^{59}$. E Incluso se vivieron momentos de abierta pero cordial discrepancia entre los cabildos, más avanzados en materia política y alentados por la nunciatura para movilizarse en clave pactista para usar "derechos políticos" y "recabar de los poderes públicos la defensa de la religión", y el obispo Catalina del Amo, quien se negó a participar en la elección de senador hasta recibir el beneplácito papal en $1877^{60}$.

A partir de aquí y hasta el final del régimen de la Restauración, lo cierto es que la colaboración mutua de la política institucional y del clero diocesano fue la norma. El gobierno demostraría su buena disposición para entenderse con la Iglesia avisando que jurar la constitución no era hacer "cosa alguna contraria a las leyes de Dios y de la Iglesia". E incluso fue frecuente la colaboración del poder municipal con el clero para disponer medidas que garantizasen el orden público, la condena de la blasfemia y la falta de respeto pública a las manifestaciones religiosas. Hechos que eran difundidos y aplaudidos en los boletines diocesanos ${ }^{61}$. A pesar de que no faltaron algunas condenas desde el púlpito hacia el liberalismo, como el caso del magistral del cabildo catedral de Santo Domingo de La Calzada, lo cierto es que el clero se cuidó de hacer manifestaciones políticas beligerantes y directas contra el Estado a pesar de defender

56. Boletín Eclesiástico Oficial del obispado de Calahorra (BEOC), 7 de febrero y 6 de julio de 1874, y 23 de enero de 1875.

57. BEOC, 6 de noviembre de 1875 .

58. BEOC, 27 de diciembre de 1875, p. 323. ACDC, Serie, Guía-inventario de los antiguos legajos ss. XIX, sig. 800/8-3. ACDC, Serie, Libro de actas capitulares, sig. 178, 30 de enero de 1875.

59. ACDC, Serie, Papeles de obispos, Gabino Catalina del Amo, sig. 7/28/3/3.

60. ACDC, Serie, Libro de actas capitulares, sig. 179, 20 y 23 de marzo de 1877, y 10 de mayo de 1877. 100.

61. Para conocer los casos véase: Cañas Díez, S. "El movimiento obrero...", op. cit., p. 
la inocencia de su compañero ${ }^{62}$. Al fin y al cabo las recomendaciones hechas desde el Vaticano, transferidas por la nunciatura, y de la jerarquía diocesana indicaban que en las iglesias se debían evitar los pronunciamientos políticos. No tanto por haber aceptado de pleno el régimen liberal sino para mantener unido al catolicismo español y respetar las disposiciones pontificias.

En cambio, en el caso concreto de los debates sobre la reducción del presupuesto de la Iglesia de 1890 sí que notamos una mayor crítica hacia algunas posturas parlamentarias y legales, basadas en la defensa de lo acordado en el Concordato de 1851, para lo que la diócesis riojana se unió a la propuesta del cabildo metropolitano de Zaragoza ${ }^{63}$. Y también hubo detracciones en la defensa del apoliticismo clerical, en unión en este caso del arzobispado de Burgos, que el propio Sagasta cuestionaba en 1883 desde el gobierno, o contra el restablecimiento de la libertad académica en 1881, otra medida defendida por el prócer riojano. En definitiva, fueron las aperturas del régimen vividas durante los gobiernos liberales de Sagasta las que causaron la crítica y la oposición de la Iglesia riojana, totalmente contraria a las libertades de conciencia, prensa y asociaciones, entendiendo que suponían un peligro para el clero, daban a las a los "ataques contra la religión" originados desde doctrinas laicas y anticlericales u otros credos religiosos no católicos, y eran una revisión unilateral de las condiciones dadas al inicio de la Restauración ${ }^{64}$. Mucho más radical fue la oposición y el movimiento generado para frenar el traslado de la silla episcopal desde Calahorra a Logroño, fuente de graves tumultos en la sede calagurritana en $1892^{65}$, si bien la historiografía defiende la idea de la neutralidad episcopal en dejar las cosas como estaban por tratarse de un asunto de rivalidad entre Logroño y Calahorra y en donde confluyeron distintas tensiones sociales más que religiosas ${ }^{66}$.

A pesar de las tiranteces producidas con los gobiernos liberales, la posición conjunta de la Iglesia diocesana trataba de lograr la unión del catolicismo español mediante una apuesta por el catolicismo social y el movimiento político católico sin salirse de las leyes vigentes, al tiempo en que se trataba de presionar a

62. Protesta del clero con motivo del procesamiento incoado al DR. Don Joaquín Linage Pineda, Canónimogo Magistral de la Santa Iglesia de Santo Domingo de la Calzada, Santo Domingo de la Calzada, Imprenta de José Sáenz Moreno, 1899.

63. ACDC, Serie, Libro de actas capitulares, sig. X, 27 de febrero de 1892.

64. Cañas Díez, S. "El movimiento obrero...", op. cit., p. 100.

65. Magníficamente tratado en: San Felipe Adán, M. A. El obispo Fidel García (18801927). La diócesis de Calahorra y La Calzada tras el concordato de 1851, Logroño, Universidad de La Rioja e Instituto de Estudios Riojanos, 2008, pp. 109-247.

66. ACDC, Serie, Libro de actas capitulares, sig. X, 26 de julio de 1892. Sáinz Ripa, E. Sedes episcopales de La Rioja, vol. IV, pp. 428 y 451. Gil Andrés, C. "¡Abajo Logroño! Los motines de Calahorra de 1892. Lecturas para la historia", Kalakorikos, 14, 2009, pp. 31-56. San Felipe, M. A. "Los motines de 1892 en Calahorra: la repercusión en la prensa nacional e internacional de un conflicto local", Brocar, 34, 2010, pp. 139-172. 
los gobernantes para lograr los fines ideológicos y materiales de la Iglesia ${ }^{67}$. Una orientación puesta de manifiesto desde 1891 por la publicación de la encíclica Rerum novarum de León XIII. Esto es lo que se hizo en todo momento desde la prensa oficial del obispado y desde el cabildo catedral de Calahorra, cuando se trató de influir en los distintos gobiernos para que resolviesen las reformas legales que modernizaban España de acuerdo con sus postulados ideológicos, y también se cargaban las tintas contra los efectos perjudiciales de las libertades y derechos que se iban concediendo en España y que resultaban contrarios a los preceptos católicos oficiales ${ }^{68}$.

Pero en el total de casos estudiados no encontramos una condena explícita del liberalismo ni tan contundente como en épocas pasadas, sino más bien el aprovechamiento de las distintas leyes y la preeminencia institucional sociocultural para tener más presencia activa en la vida popular y convencer a la población de que sus postulados eran los mejores y los válidos para quien se considerase católico. Sin embargo, lo que sí que empezó a darse ya desde los primeros tiempos de la Restauración fue la condena explícita de las ideologías obreristas o de clase, como lo demuestra la reedición en 1876 de un folleto de 1861 del obispo Monescillo donde se condenaba el socialismo ${ }^{69}$. Hecho que, lógicamente, no tuvo ningún tipo de consecuencia legal ni chocó con los límites constitucionales. Y eso que la oposición frontal a las ideologías socialistas y al laicismo liberal aumentó a medida que avanzó el siglo XX, y los ataques anticlericales se hicieron más visibles y espectaculares, como en 1909, mientras que se trataba de crear y consolidar el movimiento social católico en oposición al movimiento obrero, al anticlericalismo popular y al laicismo burgués ${ }^{70}$.

Ahora bien, tampoco la propia Iglesia tuvo reparos en dar el visto bueno a la obra El liberalismo es pecado, de F. Sardá, en 1887 mientras ordenaba retirar la Refutación de los errores contenidos en el opúsculo El liberalismo es pecado, del canónigo Pazos por no ser un texto "sano de doctrina"71. Una obra como la de Sardá que si bien está documentado fue todo un éxito de ventas en el territorio diocesano riojano ${ }^{72}$, su popularidad entre el clero no fue óbice para que este autor fuese advertido por León XIII por contribuir a la discordia entre los católicos ${ }^{73}$. Y es que pese a las tensiones que las reformas políticas y legales enfrentaban a la Iglesia con las autoridades nacionales, todavía los ecos de la

67. Revuelta González, M. La Iglesia española en el siglo XIX: desafíos y respuestas, Madrid, Universidad Pontificia de Comillas, 2005, pp. 67 y ss.

68. Para conocer todos los casos véase: Cañas Díez, S. "Iglesia y movimiento obrero...", op. cit., p. 100 y ss., y "Asociacionismo católico-riojano...", op. cit., p. 2942.

69. BEOC, 1 de noviembre de 1861.

70. Cañas Díez, S. "Crisis...".

71. BEOC, 30 de abril de 1887.

72. Sáinz Ripa, E. Sedes..., op. cit., pp. 443-444.

73. BEOC, 30 de abril de 1890. 
lucha fueron más fuertes aunque menos conocidas en el seno del catolicismo. Tanto ente los legos como en los eclesiásticos ${ }^{74}$.

También es cierto que la incidencia del pontificado de León XIII y sus textos, y el cambio de actitud y planteamiento frente al liberalismo europeo tiene más que ver con la consolidación del liberalismo en el orbe occidental que con un cambio en el seno de la cabeza de la Iglesia ${ }^{75}$. El planteamiento de confrontación y cerrazón en sí misma de la Iglesia de Pío IX no había dado sus frutos y estaba ya agotado. Y mostrando un talante posibilista, se propuso aceptar bajo determinadas condiciones el mundo moderno para poder así articular un movimiento católico para ocupar las instituciones y defender los principios de la Iglesia. Pero en la España de la Restauración la aplicación de estas medidas novedosas supuso una fuente de conflictos en el seno de una jerarquía que no entendió bien esta situación moderna, dejando a un lado la actitud siempre combativa de los sectores reaccionarios del catolicismo español cuya lucha contra el liberalismo no terminó jamás.

Analizar la importancia de los distintos obispos y vicarios capitulares también es interesante para entender esta tesitura a nivel diocesano. Por ejemplo, así como Catilina del Amo muestra el paso de la Iglesia de Pío IX a León XIII, con la presencia arrolladora de una personalidad política tan fuerte como Cascajares se agudizó la postura diocesana en torno al catolicismo social hasta el final del periodo, por cuanto apenas vemos cambios programáticos con el deán Palacios o el cardenal Aguirre ya en el siglo XX. Simplemente cobró más importancia el combate contra la prensa moderna no católica y se reforzó el movimiento católico en forma de sindicalismo agrario, pero la defensa del orden político y socioeconómico de la democracia liberal seguía aceptándose como un mal menor frente al progresivo fortalecimiento del movimiento obrero $^{76}$. Lo cierto es que en referencia al cardenal Cascajares, cuyos textos fueron reproducidos y cuya figura fue ensalzada en la creciente prensa católica riojana ${ }^{77}$, no vemos que en relación a la Iglesia riojana se cumpla su caracterización general de ser un personaje mucho más afincado en la política que otros obispos, por cuanto trató de formar un partido conservador que sustituyese al de Cánovas ${ }^{78}$. Aunque lo cierto es que la jerarquía eclesiástica

74. J. L. Ruiz Sánchez, "Jerarquía católica y conflictividad...", op. cit., p. 11.

75. Y no solo por la cuestión social despachada en Rerum Novarum, de 1891, sino también por Diuturnum, de 1881, Inmortale Dei, de 1885, Libertas, de 1886, y Au Milieu, de 1892.

76. Cárcel Ortí, V. Historia de la Iglesia en la España contemporánea: siglos XIX y XX, Madrid, Ediciones Palabra, 2002, p. 112.

77. Además de La Rioja Católica y el BEOC, otros diarios como El Compañero, El Heraldo de Haro, El Noticiero Calahorrano, La Lealtad Riojana y La Opinión, aparecieron en esta época para engrosar las filas del periodismo y la publicística del catolicismo.

78. Casas Rabasa, S. "Ser obispo en la España de la Restauración", Jerónimo Zurita, 87, 2012, p. 352. 
riojana se movía cómodamente en su acercamiento al régimen burgués y dinástico, a pesar de sus reservas y de otorgar en todo momento prioridad a su propia subsistencia y reproducción en la sociedad antes que a la salvación del modelo político construido en 1876.

\section{Conclusiones: en misa y repicando}

La larga etapa de la Restauración alfonsina es el momento histórico de mayor estabilidad política durante toda la historia contemporánea junto al actual. Posiblemente por eso se las equipara desde el terreno político con tanta frecuencia, dejando de lado comparaciones extravagantes que solo utilizan el pasado como fuente de legitimación presente. Para que resultase así, el cambio de paradigma de la Iglesia a la hora de aceptar la monarquía constitucional y unas mínimas bases liberales fue clave: si la política liberal, sus distintas opciones por transformar la realidad española, habían dividido al catolicismo español en todo el desarrollo anterior del siglo XIX abriendo más la brecha tras la revolución del 68, el régimen iniciado en 1876 sirvió como un intento de reagruparse y modernizarse. Por eso se produjo una alianza entre la Iglesia y el Estado.

Aunque la unión no fue totalmente posible y conocemos episodios que muestran la radicalidad del integrismo católico de cara a condenar el régimen liberal, los prelados de La Rioja estuvieron siempre al lado de los postulados vaticanistas y por ende del movimiento católico, por lo que mantuvieron a éste al lado del sistema político durante el tiempo que duró el turno dinástico, pese a acoger con beneplácito la dictadura en 1923. Un hecho que solo se puede entender por la estabilidad que produjo para sus intereses la monarquía de Alfonso XII. Tras los efectos negativos de la "monarquía revolucionaria" de Amadeo I y "la anarquía de la República", la Constitución de 1876 garantizaba el confesionalismo católico nacional, y aprovechado este revulsivo y las distintas leyes aprobadas en pos de los derechos civiles, la de asociación, la de educación y la de prensa fundamentalmente, la Iglesia recuperó parte del terreno perdido y tuvo de nuevo más presencia activa en la vida popular tras el descalabro que supuso el Sexenio Democrático. Lo que se tradujo en un aumento de las misiones y la constitución de círculos obreros, sindicatos y periódicos católicos por todo el territorio diocesano.

En este sentido vemos que la Restauración fue un sistema político que brilló por su pragmatismo, lo que la mejora entre las relaciones Iglesia-Estado puede demostrar en tanto en cuanto se les blindó como credo nacional pero se le exigió apoyo a cambio y silenciar las voces más recalcitrantes contra el liberalismo. Y la misma estabilidad proporcionada por los pactos de las élites mayoritarias y de éstas con el clero, fue causa de su propio éxito a finales del siglo XIX como puede explicar su caída en la primera década del siglo 
XX. Murió de éxito por decirlo de una forma coloquial, pues la mejora de las relaciones del clero con el poder motivó que las posiciones críticas con el crecido poder de la Iglesia, fueran parlamentarias o no, exagerasen las cesiones hechas por el gobierno para tener más control sobre ella. Y al revés, esquematizaron al clero como mero garante del poder de la burguesía en el terreno político y económico.

Pero lo cierto es que el sistema político no pudo ni pretendió mutar el alma de la Iglesia, solo quería que se amoldase a la ley para lograr la modernidad a través de la estabilidad social. Los gobiernos liberales de Sagasta y su caudal de cambios sí que fueron asuntos más peliagudos y tensos, pues si ya el regalismo canovista era mirado con recelo por los sectores más conservadores, no podemos omitir que la Iglesia trató de influir frente a los gobiernos liberales, herederos del progresismo, quienes simultáneamente se sentían molestos con la pretensión del clero de querer controlar la vida nacional y su decidida defensa y apuesta de cara a aumentar sus privilegios y defender sus intereses particulares. En ese sentido, destaca el pragmatismo de la Iglesia riojana. Supo mostrarse más abierta y tímidamente aperturista para usar las herramientas que el régimen de 1876 le aportó. Y aunque no rechazó de frente los textos antiliberales, supo silenciarlos para no dar lugar a un enfrentamiento abierto contra el Estado que hubiera podido conllevar la disgregación del catolicismo español entre una tendencia puramente contrarrevolucionaria y otra menos conservadora.

Con todo, es indudable que gracias a este pacto podemos explicar el freno del carlismo y del republicanismo, como opciones políticas marginales. Pero también el auge del movimiento obrero que cada vez era más fuerte aunque tuvo que competir con el sindicalismo católico. Por otro lado, aunque no se terminase con la hostilidad hacia el liberalismo por parte del integrismo ni se frenó la crítica de la Iglesia ante sus efectos prácticos cuando contradecían la posición oficial del catolicismo, sí que se redujo su influencia en amplias capas de la población católica que ni que decir tiene era el credo religioso mayoritario. Pero tampoco se puede minusvalorar la fuerza del integrismo, más presente en la prensa que en la calle y en los cabildos en el caso riojano, porque su sector más radical fue tan fuerte como para impedir el éxito de de la Unión Católica en 1881 como nuevo partido político católico.

En lo referente a la democracia liberal, lo cierto es que la propia división insalvable entre católicos no hizo posible la creación de una democracia cristiana moderna como se daba en otras partes de Europa, entendiendo como tal a aquellos demócratas de inspiración cristiana en lo político que simultáneamente trataban de cumplir con un programa social de tinte reformistas ${ }^{79}$. Aunque al final del pontificado de León XIII se planteaba ya un

79. Laboa, J. M. La Iglesia del siglo XIX..., op. cit., p. 286. 
primer debate sobre el término, en esta época la democracia cristiana se terminó entendiendo más como una crítica al paternalismo y clericalismo del catolicismo social, pues en esta época el concepto de democracia cristiana hacía referencia a la acción social popular, alejando cualquier otra identificación liberal-democrática ya iniciada a principios del siglo XX por parte de sus impulsores ${ }^{80}$.

\section{Bibliografía}

Artola, M., Partidos y Programas políticos, 1808-1936. I. Los partidos políticos, Alianza, Madrid, 1991.

Avilés, J., Elizalde, M. M. y Sueiro, S., Historia política de España 1875-1939, Istmo, Madrid, 2002.

Barrón García, J. I., La cuestión religiosa en España, 1875-1912. Iglesia y Estado. Clericalismo y anticlericalismo, Ediciones 19, Madrid, 2015.

Barrón García, J. I., La Iglesia católica y los estados de Europa Occidental y Norteamérica 1875-1912, Ediciones 19, Madrid, 2015.

Botti, A., Cielo y dinero. El nacionalcatolicismo en España (1871-1975), Alianza, Madrid, 1992.

Box, Z., "La tesis de la religión política y sus críticos: aproximación a un debate actual", Ayer, 62, 2006, pp. 195-230.

Cajas Valero, A., El Gobernador civil y el Estado centralizado del siglo XIX, Madrid, Ministerio de Administraciones Públicas, 1999.

Callahan, W. J., La Iglesia católica en España (1875-2002), Crítica, Barcelona, 2002.

Cañas Díez, S., "Crisis de la religiosidad tradicional frente a la modernidad entre los siglos XIX-XX: el ejemplo de la Diócesis de Calahorra y La Calzada", Historia Actual Online, 43, 2017, pp. 79-89.

Cañas Díez, S., "Asociacionismo católico-riojano durante la Restauración (18761923)", Folguera, P. et al. (Eds), Pensar con la historia desde el siglo XXI, UAM, Madrid, 2015, pp. 2937-2955. http://doi.org/10.15366/pensarhisXXI2015.

Cañas Díez, S., "El catolicismo español frente a la Unificación de Italia", en Granito, E. (coord.), Un popolo uno Stato, Plectica, Salerno, 2012, pp. 189222.

Cañas Díez, S., "Iglesia y movimiento obrero en La Rioja (1876-1923)", Historia Actual Online, 35, 2014, pp. 93-112.

80. Montero, F. "Las derechas y el catolicismo español: del integrismo al socialcristianismo" Historia y Política, 18, 2007, p. 107. 
Cañas Díez, S., "Iglesia y prensa española frente a la Unificación de Italia. Sagasta y el debate sobre el poder temporal del Papa", Brocar, 34, 2010, pp. 77-114. http://doi.org/10.18172/brocar.1647.

Cañas Díez, S., "La unificación de Italia vista por la Iglesia española: el caso de Calahorra", Kalakorikos, 16, 2011, pp. 31-77.

Capellán, G., "El problema religioso en la España contemporánea: Krausismo y catolicismo liberal", Ayer, 39, 2000, pp. 207-244.

Cárcel Ortí, V., Historia de la Iglesia en la España contemporánea: siglos XIX y XX, Ediciones Palabra, Madrid, 2002.

Casanova, J. y Gil Andrés, C., Historia de España en el siglo XX, Ariel, Barcelona, 2012.

Casas Rabasa, S., "Ser obispo en la España de la Restauración", Jerónimo Zurita, 87, 2012, pp. 339-361.

Costa, J., Oligarquía y caciquismo como forma actual de gobierno en España: urgencia y modo de cambiarla, Úbeda, Asociación Cultural Ubetense Alfredo Cazabán Laguna, 2012. (Original de 1901).

De la Cueva, J., "Católicos en la calle: la movilización de los católicos españoles, 1899-1923", Historia y política, 3, 2000, pp. 55-80.

De la Cueva, J., "Clericalismo y movilización católica en la España de la Restauración", en de la Cueva Merino, J. y López Villaverde, A. L. (coord.), Clericalismo y asociacionismo católico en España: de la restauración a la transición, Cuenca, Universidad de Castilla-La Mancha, 2005, pp. 27-50.

De la Cueva, J. Clericales y anticlericales. El conflicto entre Confesionalidad y Secularización en Cantabria (1875-1923), Universidad de Cantabria, Santander, 1994.

Delgado Idarreta, J. M., "La Rioja", en Valera Ortega, J. (Dir.), El poder de la influencia: geografía del caciquismo en España (1875-1923), Marcial Pons, Madrid, 2001, pp. 497-515.

Esdaile, C., La etapa liberal: 1808-1898, en Lynch, J. (Dir.), Historia de España, vol. 17, El País, Madrid, 2007.

Esteban de Vega, M., "Católicos contra liberales: notas sobre el ambiente ideológico salmantino en la Restauración", Studia Historica, 4, 1987, pp. 51-69.

Fontana, J., "Respuesta al ensayo bibliográfico de Jesús Millán", Ayer, 98, 2015, pp. 257-260.

Fontana, J., La época del liberalismo, Crítica y Marcial Pons, Barcelona, 2007.

Fusi, J. P., Historia mínima de España, Turner, Madrid, 2012.

Gil Andrés, C. “¡Abajo Logroño! Los motines de Calahorra de 1892. Lecturas para la historia", Kalakorikos, 14, 2009, pp. 31-56.

Gil Andrés, C., Echarse a la calle: amotinados, huelguistas y revolucionarios (La Rioja, 1890-1936), Universidad de Zaragoza, Zaragoza, 2000. 
Gil Andrés, C., Protesta popular y orden social en La Rioja de fin de siglo, 18901905, Instituto de Estudios Riojanos, Logroño, 1995.

González Calleja, E., "La razón de la fuerza. Una perspectiva de la violencia política en la España de la Restauración", Ayer, 13, 1994, pp. 85-114.

Jover Zamora, J. M., "La época de la Restauración. Panorama político-social, 1875-1902", en Tuñón de Lara, M. (Dir.), Historia de España, vol. VIII, Barcelona, 1981.

Laboa, J. M., La Iglesia del siglo XIX. Entre la Restauración y la Revolución, Universidad Pontificia de Comillas, Madrid, 1994.

Louzao Villar, J., "Las imágenes de lo sagrado o cómo ser católico entre cambios y continuidades (C. 1875-1931)", Historia Contemporánea, 51, 2015, pp. 455-485.

Louzao Villar, J., Soldados de la fe o amantes del progreso. Catolicismo y modernidad (1890-1923), Genueve Ediciones, Logroño, 2011.

Martí Gilabert, F., Politica religiosa de la Restauración, 1875-1931, Rialp, Madrid, 1991.

Millán, J., "La formación de la España contemporánea: el agotamiento explicativo del fracaso liberal", Ayer, 98, 2015, pp. 243-256.

Millán, J. y Romeo, M. C., “¿Por qué es importante la revolución liberal en España? Culturas políticas y ciudadanía en la historia española", en Burguera, M., y Schmidt-Nowara, C. (Eds.), Historias de España contemporánea. Cambio social y giro cultural, Universidad de Valencia, Valencia, 2008, pp. 17-43.

Montero, F., "El catolicismo español finisecular y la crisis del 98”, Studia histórica, 15, 1997, pp. 221-237.

Montero, F., "El peso del integrismo en la Iglesia y el catolicismo español del siglo XX", Melanges de la Casa de Velázquez, 44, 2014, pp. 131-156.

Montero, F., "La Iglesia católica ante el sistema político de la Restauración", en Portero, F. y Tusell, J. (Eds.), Antonio Cánovas y el sistema político de la Restauración, Biblioteca Nueva, Madrid, 1998, pp. 207-210.

Montero, F., "La relación Iglesia-sociedad en la España de la segunda mitad del siglo XIX", Revista de historia contemporánea, 3, 1984, pp. 87-98.

Montero, F., "Las derechas y el catolicismo español: del integrismo al socialcristianismo", Historia y Política, 18, 2007, pp. 101-128.

Montero, F., El movimiento católico en España, Eudema, Madrid, 1993.

Payne, S. G., El catolicismo español, Planeta, Barcelona, 2006.

Preston, P., "Persecuted and Persecutors: Modern Spanish Catholicism", European History Quarterly, 20, 1990, pp. 285-292.

Ramón Solans, J. F., "'El catolicismo tiene masas'. Nación, política y movilización en España, 1868-1931", Historia Contemporánea, 51, 2015, pp. 427454. 
Revuelta González, M., "La recuperación eclesiástica y el rechazo anticlerical en el cambio de siglo ", en García Delgado, J. L. (ed.), España entre dos siglos (1875-1931). Continuidad y cambio, Madrid, 1991, pp. 213-234.

Revuelta González, M., La Iglesia española en el siglo XIX: desafíos y respuestas, Universidad Pontificia de Comillas, Madrid, 2005.

Robles, C., Insurrección o legalidad: los católicos y la Restauración, CSIC, Madrid, 1988.

Ruiz Sánchez, J. L., "Jerarquía católica y conflictividad en la Iglesia española de finales del siglo XIX. Orígenes y fundamentos", Kalakorikos, 14, 2009, pp. 9-30.

Sáinz Ripa, E., "La religiosidad en La Rioja durante el siglo XIX", Berceo, 83, 1972, pp. 159-184.

Sáinz Ripa, E., Sedes episcopales de La Rioja, vol. IV, Diócesis de Calahorra-La Calzada-Logroño, Logroño, 1994.

San Felipe Adán, M. A., El obispo Fidel García (1880-1927). La diócesis de Calahorra y La Calzada tras el concordato de 1851, Universidad de La Rioja e Instituto de Estudios Riojanos, Logroño, 2008.

San Felipe, M. A., "Los motines de 1892 en Calahorra: la repercusión en la prensa nacional e internacional de un conflicto local", Brocar, 34, 2010, pp. 139-172. http://doi.org/10.18172/brocar.1649.

Seco Serrano, C., De los tiempos de Cánovas, Real Academia de la Historia, Madrid, 2004.

Sierra, M., Peña, M. A. y Zurita, R., Elegidos y elegibles. La representación parlamentaria en la cultura del liberalismo, Madrid, Marcial Pons, 2010.

Suárez Cortina, M., (Ed.), Las máscaras de la libertad. El liberalismo español 1808-1950, Marcial Pons y Fundación Práxedes Mateo Sagasta, Madrid, 2003.

Suárez Cortina, M., "Anticlericalismo, religión y política en la Restauración", en La Parra, E. y Suárez Cortina, M. (Eds.), El anticlericalismo español contemporáneo, Biblioteca Nueva, Madrid, 1998.

Suárez Cortina, M., "El liberalismo democrático en España: de la Restauración a la república", Historia y política, 17, 2007, pp. 121-150.

Suárez Cortina, M., "La ideología liberal en la historia del constitucionalismo español del siglo XIX: la cuestión religiosa", en Caballero, J.A., Delgado, J. M. y Viguera, R. (Eds.), El debate constitucional en el siglo XIX. Ideología, oratoria y opinión pública, Marcial Pons, Madrid, 2015, pp. 35-65.

Suárez Cortina, M., "Radicalismo y reformismo en la democracia española de la Restauración", Berceo, 139, 2000, pp. 49-66.

Suárez Cortina, M., Entre cirios y garrotes. Política y religión en la España contemporánea, 1808-1936, Universidad de Castilla La Mancha, Cuenca, 2014. 
Súarez Cortina, M., La España liberal (1868-1917). Política y sociedad, Síntesis, Madrid, 2006.

Valera Ortega, J., Los amigos políticos: partidos, elecciones y caciquismo en la Restauración (1875-1900), Marcial Pons, Madrid, 2001. 